\title{
La arqueología virtual como herramienta didáctica y motivadora
}

\author{
Antonio Gabriel Gisbert Santaballa \\ Máster en Arqueología, Patrimonio e Historia Marítima por la Universidad de Cádiz \\ y miembro del Departamento de Educación del Gobierno de Navarra \\ agsantaballa@gmail.com
}

\section{Extracto}

El presente trabajo tiene como objetivo abordar posibles soluciones al desinterés que puede surgir en torno al aprendizaje de la Historia y de los yacimientos arqueológicos por parte de los alumnos de educación secundaria obligatoria (ESO) y bachillerato. Para ello, nos hemos centrado en experiencias de arqueología virtual que contribuyen a la motivación e interactividad de los visitantes, a través de bibliografía especializada, y de la visita y el análisis de diferentes yacimientos españoles. Los resultados de dicho análisis han sido que existen experiencias muy interesantes en España y en otros países de nuestro entorno, que se basan en reconstrucciones tridimensionales, en entornos virtuales, en experiencias inmersivas y en una cuidada narración. Las conclusiones se centran en señalar las ventajas de estos elementos a la hora de plantear actividades de enseñanza-aprendizaje con alumnos de secundaria y bachillerato, ya que aumentan la motivación y el interés que estos puedan experimentar por el conocimiento del pasado histórico.

Palabras clave: arqueología; motivación; entornos virtuales; educación patrimonial; vídeo interactivo; educación secundaria obligatoria (ESO); bachillerato. 


\title{
Virtual archaeology as a didactic and motivating tool
}

\author{
Antonio Gabriel Gisbert Santaballa
}

\begin{abstract}
The present essay deals with suitable solutions to the disinterest that may arose within History and archaeology learning in secondary education students (12-17 years old). Therefore, this essay is going to focus on different virtual archaeology experiences that foster visitors' motivation and interest. Methodology used has been the analysis of specialized essays, and the visit of certains archaeological sites of Spain. The results of these analysis are that several interesting experiences are being developed, and that those experiences are focused on 3D reconstructions, virtual environments, immersive experiences, and the use of story-telling techniques. Finally, conclusions deals with the suitability and advantages of these elements to plan effective, motivating and engaging history activities for secondary education students.
\end{abstract}

Keywords: archaeology; student motivation; virtual classrooms; heritage education; interactive video; secondary education.

Citation: Gisbert Santaballa, A. G. (2019). Virtual archaeology as a didactic and motivating tool. Tecnología, Ciencia y Educación, 13, 119-147. 


\section{Sumario}

1. El desinterés de los alumnos de secundaria y bachillerato por la Historia

2. La arqueología virtual como solución

2.1. Estado de la cuestión

2.2. La interactividad y la importancia del guion

3. Investigación sobre arqueología virtual y difusión educativa en nuestro entorno

3.1. Posicionamiento metodológico

3.2. Muestra

3.3. Técnicas, materiales e instrumentos

4. Resultados

4.1. Paneles y cartelería. Casa de Hippolytus (Alcalá de Henares)

4.2. Vídeos como presentación previa. Puerto Fluvial de Caesaraugusta (Zaragoza)

4.3. Reconstrucción en 3D de la Tumba Regolini-Galassi (Italia). Proyecto Etruscanning

4.4. Digitalización de espacios históricos y arqueológicos: visita virtual a la Alhambra (Granada) y a la Cueva Chauvet-Pont d'Arc (Francia)

4.5. Vídeo mapping. Sant Climent de Taüll (Lleida)

4.6. Gafas de realidad virtual. Past View (Sevilla)

5. Discusión y conclusiones

5.1. Discusión

5.2. Conclusiones

6. Prospectiva

Referencias bibliográficas 


\section{El desinterés de los alumnos de secundaria y bachillerato por la Historia}

El presente trabajo nace del interés de fomentar la motivación de los alumnos hacia la asignatura de Historia en secundaria y bachillerato. ¿Cómo es posible que, año tras año, haya sido mayor el número de alumnos que se han presentado a las pruebas de acceso a la universidad (PAU) por Filosofía, una materia eminentemente teórica, que a Historia, una asignatura con tantas vertientes prácticas? (Estadísticas PAU, curso 2014/2015, de la Universidad de Castilla-La Mancha y del País Vasco).

Una de esas vertientes prácticas es, precisamente, la arqueología y el estudio del pasado histórico a través de los restos de cultura material. Sin embargo, de nuevo se nos presenta otra problemática: ¿resulta el patrimonio arqueológico que visitan los alumnos de secundaria y bachillerato atractivo, motivante y significativo para ellos?; ¿garantizan los mecanismos de difusión educativa de estos lugares una adecuada comprensión acerca de las sociedades del pasado histórico?

El trabajo que aquí presentamos va a analizar algunas producciones de arqueología virtual que podemos encontrar en la actualidad en nuestro país y en otros países de nuestro entorno con el objetivo de subrayar las ventajas didácticas que poseen, en cuanto a motivación y comprensión del pasado por parte de los jóvenes.

\section{La arqueología virtual como solución}

La hipótesis principal que se persigue validar con este trabajo es cómo la arqueología virtual contribuye a aumentar la motivación y el interés de los estudiantes hacia el aprendizaje de la Historia y qué recursos educativos ofrece.

\subsection{Estado de la cuestión}

Existe un creciente interés por parte de diferentes autores, sectores e investigadores acerca de las conexiones existentes entre el patrimonio y su dimensión educativa. En este sentido, son especialmente importantes diferentes congresos que se han llevado a cabo sobre la materia. EI IV Congreso Internacional en Educación Patrimonial -celebrado en noviembre de 2018 y organizado por el Ministerio de Educación, Cultura y Deporte- revela un interés cada vez mayor por parte de las Administraciones públicas de innovar y actualizar los mecanismos de difusión educativa del patrimonio existente en nuestro país. 
Dentro de los estudios sobre educación patrimonial, la arqueología virtual es el campo que más expansión ha experimentado en los últimos años. Algunos ejemplos de esta expansión los encontramos en los cursos ofertados por diferentes universidades, en el Máster en Patrimonio Virtual de la Universidad de Alicante o en la celebración en Valencia, en septiembre de 2016, de Arqueología 2.0. VIII Congreso Internacional de Arqueología e Informática Gráfica, Patrimonio e Innovación, organizado por la Sociedad Española de Arqueología Virtual (SEAV), y que versó sobre documentación 3D avanzada, modelado y reconstrucción de objetos patrimoniales, monumentos y sitios.

Por otro lado, monografías como las de Bellido (2001) supusieron un punto de arranque en la conceptualización de la nueva disciplina y en lo que implicaba su uso en museografía y en la difusión del patrimonio histórico. Su conceptualización de los diferentes niveles que se requieren en un entorno virtual (generación de imágenes no procedentes de la realidad, tridimensionalidad de las mismas, posibilidad de inmersión e interactividad) servirán para basar el análisis de los modelos presentados en este artículo.

Sobre la virtualización de museos para mejorar la divulgación de los mismos, encontramos a Sabbatini (2003), quien señala las limitaciones del museo tradicional como instrumento de acceso a la cultura y el modo en que la virtualización permite establecer ricas conexiones entre el objeto mostrado en el museo, su contexto y otros objetos expuestos para crear una experiencia cultural relevante, y de lo que veremos un ejemplo característico en este trabajo al analizar la Tumba Regolini-Galassi. En una línea parecida, acerca del uso de espacios y técnicas de educación no formal (como yacimientos o museos) para la enseñanza de la Historia, nos hablan también Hernández y Rojo (2012), centrando su estudio en la problemática que aborda este artículo: ¿qué técnicas deben utilizarse para divulgar el patrimonio arqueológico de una forma significativa, didáctica y motivadora, que no exija altos grados de abstracción por parte del estudiante? Sobre el tratamiento del patrimonio en secundaria y bachillerato, precisamente, encontramos a Prats (2001), Rico y Ávila (2003) y González (2011), quienes no solo inciden en su importancia a la hora de proteger dicho patrimonio del expolio y la destrucción, sino que señalan su importancia social primordial a la hora de comprender el mundo, configurar identidades y crear perfiles de «consumidores culturales».

Por otro lado, sobre las ventajas en cuanto al uso de las nuevas tecnologías en el aula, encontramos a Ortiz (2011), quien señalará la motivación, el interés, la interacción y la interdisciplinariedad, entre otras, y que son elementos clave en la argumentación de este trabajo. Sin embargo, también conviene tener en cuenta a autores como Marqués (2013), que nos habla sobre los inconvenientes de estos soportes y nos recuerda que lo relevante debe ser siempre lo educativo, no lo tecnológico. Desarrollando esta idea, autores como Sancho (2008) y Albert (2014) introducen el término tecnologías del aprendizaje y el conocimiento (TAC), que intenta superar al de tecnologías de la información y la comunicación (TIC), y que pone en primer lugar el elemento educativo frente al tecnológico. De este modo, los ejemplos de arqueología virtual mostrados en este análisis tendrán su foco siempre puesto en su potencialidad educativa y motivadora para el estudiante, siendo la tecnología un soporte, no un fin en sí mismo. Otros autores como Rascón y Sánchez (2008) o Pujol y Economou (2009) 
inciden en las ventajas de la realidad virtual para trabajar con datos espaciotemporales, que superan la necesidad de abstracción, los conocimientos previos necesarios y el desinterés asociado a yacimientos arqueológicos «fosilizados». Schmidt (2012), por otra parte, incide en las ventajas que ofrece la contextualización de materiales y lugares arqueológicos en su adecuado marco histórico, social, geográfico, etc., a través de medios virtuales para mejorar la comprensión e interpretación de los lugares; ejemplos que veremos con detalle en la ya citada Tumba Regolini-Galassi y en la iglesia románica de Sant Climent de Taüll. Ibáñez (2014) nos habla precisamente sobre las últimas tendencias en cuanto a usos de las TIC en educación patrimonial. De forma más concreta, sobre el uso de dispositivos móviles, vamos a encontrar a Coma (2014), y en cuanto al uso de la realidad aumentada y de los códigos QR, a Silva (2013). Elementos todos ellos que comportan un alto grado de interactividad y que veremos en este trabajo aplicados a las visitas guiadas que propone la empresa Past View en Sevilla. Otro aspecto de importancia y debate es el correspondiente a la adecuación de las reconstrucciones virtuales a los intereses de los diferentes públicos que visitan los yacimientos, y si estas resultan significativas, interesantes y motivantes (Santacana y Martín, 2010). Por último, podemos citar la interactividad del visitante/estudiante con la información ofrecida por estos entornos virtuales y sus ventajas como otro de los temas centrales alrededor del estudio de la arqueología virtual como herramienta didáctica (Pujol y Economou, 2009).

\subsection{La interactividad y la importancia del guion}

La arqueología virtual nace, en parte, de la necesidad de incorporar el patrimonio a los procesos educativos a través de una mejora en su difusión; en su legibilidad por parte del público no especializado. De este modo, y a través de estas herramientas, se tiende a superar la concepción del patrimonio, de su gestión y de su difusión como un elemento ligado a la historia del arte (Santacana y Masriera, 2012) (monumentalismo centrado en elementos estéticos, formales, etc.), y, a través de la interactividad que pueden permitir las nuevas tecnologías, se utiliza el patrimonio para abordar un conocimiento extenso sobre el pasado histórico, sobre la cultura material e intelectual, sobre los usos, las costumbres y los modos de vida de las sociedades a lo largo de la historia.

A la hora de abordar una intervención virtual en el patrimonio arqueológico, es fundamental el papel que va a cobrar el guion técnico. El guion técnico correspondería a la narración, a la interpretación que el historiador va a hacer a partir de los datos arqueológicos (de las texturas y de los elementos 3D reconstruidos en este caso) de los que dispone. No debemos perder de vista este hecho, ya que las nuevas tecnologías deben ser una herramienta que nos permita acceder con mayor facilidad al conocimiento del pasado; un medio muy útil, pero no un fin en sí mismo.

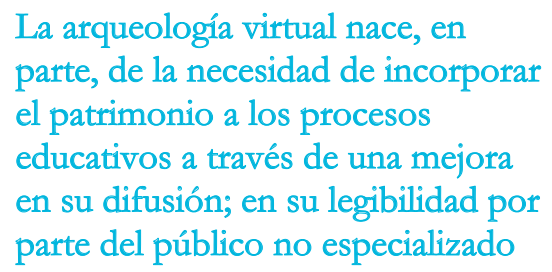

La arqueología virtual nace, en parte, de la necesidad de incorporar el patrimonio a los procesos educativos a través de una mejora en su difusión; en su legibilidad por parte del público no especializado 
En este sentido, parece muy conveniente aplicar al uso y al tratamiento de las nuevas tecnologías las consideraciones que historiadores como Barthes (1985), Duby (1994) o Mudrovcic (2005) tienen acerca de la narración (el guion técnico de una animación 3D en nuestro caso) a la hora de escribir historia (y, en nuestro caso, de difundir el patrimonio arqueológico).

Dichos autores entienden que en la Historia, como disciplina, se juntan dos significados. Por un lado, el científico, relacionado con la recolección de datos, el tamizado de los mismos, el planteamiento de hipótesis, la elaboración de teorías, etc. Sin embargo, en paralelo a este proceso, el historiador lleva a cabo una labor de interpretación, valoración y construcción de una narración a partir de dichos datos; la parte literaria de la investigación histórica, donde entra en juego la capacidad del investigador de elaborar un relato que imagine, reconstruya, complemente y dé sentido a momentos del pasado de los cuáles no se han conservado registros arqueológicos, o estos son confusos.

Lo literario de estos relatos o "guiones» presenta un elemento muy útil para el objetivo que hemos querido otorgar a la arqueología virtual en este trabajo. La elaboración de un determinado discurso, la presentación de determinados conceptos a través de técnicas «literarias», transmite emoción e intriga; emoción e intriga que, si se adecuan a los diferentes públicos que pueden llegar a visitar un yacimiento arqueológico, redundan en una mayor motivación, interés y ganas por aprender (Brown, Denning, Groh y Prusac, 2004).

De este modo, un mismo espacio arqueológico debería ser capaz de ofrecer un amplio abanico de diferentes temáticas, diferentes aspectos del pasado histórico que pudieran ser utilizados en base a los intereses y a los objetivos didácticos planteados para diferentes grupos. La reconstrucción no sería la misma para un grupo de bachillerato que para uno de secundaria; para un grupo que curse Historia del Arte que para otro que curse Historia de España. Diferentes públicos ante los cuales la arqueología virtual debería ser capaz de adaptarse, ofreciendo un abanico temático dentro del mismo yacimiento y facilitando la misión didáctica, la claridad y la comprensión de los contenidos, así como la atención a la diversidad que encontraremos en nuestras aulas (Husillos, 2013).

\section{Investigación sobre arqueología virtual y difusión educativa en nuestro entorno}

\subsection{Posicionamiento metodológico}

El posicionamiento metodológico utilizado en este trabajo va a ser de tipo cualitativo, en la medida en que va a consistir en la visita y en el análisis de diferentes medios tecnológicos de difusión patrimonial y educativa, así como en la revisión y en el estudio de bibliografía dedicada al tema. 


\subsection{Muestra}

El número de elementos de este muestreo consiste en un total de seis:

- Casa de Hippolytus (Alcalá de Henares).

- Puerto Fluvial de Caesaraugusta (Zaragoza).

- Iglesia de Sant Climent de Taüll (Lleida).

- Tumba Regolini-Galassi (Italia).

- Visitas virtuales a la Alhambra (Granada) y a la Cueva Chauvet-Pont d'Arc (Francia).

- Empresa Past View (Sevilla).

Este número de elementos busca analizar las ventajas educativas de cinco técnicas de arqueología virtual diferentes (cartelería, vídeos, vídeo mapping, entorno virtual y realidad virtual) a través de un ejemplo práctico y significativo de cada una de ellas.

\subsection{Técnicas, materiales e instrumentos}

La primera de las herramientas metodológicas utilizadas para desarrollar este proyecto consistirá en la visita a diferentes yacimientos arqueológicos del país, y de los que se llevará a cabo un análisis de sus elementos de difusión asociados a la arqueología virtual. Los yacimientos visitados serán los de la Casa de Hippolytus (Alcalá de Henares, Madrid) y el Puerto Fluvial de Caesaraugusta (Zaragoza). También serán visitadas empresas privadas, como la sevillana Past View, que dirige un proyecto de visualización virtual histórica asociada al turismo patrimonial. La visita a dichos lugares se ha realizado, en primer lugar, por motivos de cercanía y accesibilidad, y, por otro lado, por la importancia y la presencia de algunos de ellos en la literatura especializada de arqueología virtual, como es el caso de la cartelería de la Casa de Hippolytus (Rascón y Sánchez, 2008).

Un trabajo paralelo consistirá en el análisis, a través de bibliografía de experiencias de arqueología virtual llevadas a cabo en otros puntos de España y en otros países de nuestro entorno, de la tumba etrusca de Regolini-Galassi (Italia), de la Cueva Chauvet-Pont d'Arc (Francia) o de la iglesia románica de Sant Climent de Taüll (Lleida). Dichos análisis estarán acompañados por fotografías e imágenes que sirvan para ilustrar el material y los procesos descritos.

Con los datos obtenidos, en una segunda parte del artículo, se llevará a cabo una discusión acerca de los resultados obtenidos, detectando ventajas e inconvenientes en cuanto a su aplicación didáctica. 


\section{Resultados}

Llevar a cabo una tipología sobre arqueología virtual es una tarea complicada. Esta complicación viene dada por la multitud de producciones de muy diversa índole que tienen como base una reconstrucción de elementos patrimoniales y arqueológicos usando nuevas tecnologías. De este modo, se pueden considerar producciones de arqueología virtual tanto unos paneles en un yacimiento, donde incluimos reconstrucciones hechas por ordenador de un edificio, y lo mostramos junto a sus ruinas, como un proyecto de gafas de realidad virtual.

Para intentar llevar a cabo una clasificación de diferentes tipos y ejemplos prácticos, vamos a tomar como base el trabajo de Bellido (2001), una de las pioneras en lo que respecta a la teoría de la arqueología virtual. En su trabajo, esta autora ya planteaba que un entorno virtual debía cumplir cuatro requisitos:

- Generación de imágenes de creaciones propias y no procedentes de la realidad.

- Tridimensionalidad de dichas imágenes.

- Posibilidad de que el usuario se vea inmerso en esa tridimensionalidad.

- Interactividad.

Las producciones que vamos a poner como ejemplo a continuación siguen un orden creciente de complejidad y cumplen, dependiendo de la misma, los dos primeros requisitos, tres o todos.

\subsection{Paneles y cartelería. Casa de Hippolytus (Alcalá de Henares)}

Comenzaremos, en primer lugar, con la forma más habitual de utilizar las reconstrucciones en 3D ofrecidas por la arqueología virtual a la hora de difundir y presentar elementos de patrimonio arqueológico. Esta forma sería la de introducir elementos de reconstrucción virtual y modelos tridimensionales de edificios, paisajes, recreaciones de momentos históricos o de escenas de la vida cotidiana, insertándolos en una instalación de paneles y cartelería en lugares seleccionados dentro del propio yacimiento (Almansa y Señorán, 2005).

La función sería servir de soporte y de guía visual al visitante, utilizando modelos tridimensionales de los edificios existentes en una determinada época, situados frente a los restos arqueológicos en los que se basa dicha hipótesis reconstructiva, para facilitar la comprensión de los restos y del yacimiento en su conjunto.

Un buen ejemplo de esta cartelería la encontraremos en el yacimiento arqueológico de la Casa de Hippolytus en Alcalá de Henares (Madrid). El yacimiento ha sido interpretado como un colegio de jóvenes (collegium invenum), donde los hijos de las familias relevantes 
de la ciudad de Complutum recibían educación, formación religiosa y realizaban actividades lúdicas, o, en otros casos, como un complejo termal suburbano (García-Entero, 2004). Su construcción se sitúa en el siglo I d. C., aunque su fase principal como colegio de jóvenes, que es en el que se va a basar la musealización, se sitúa entre los siglos III y IV d. C.

La musealización de la Casa de Hippolytus en 1999, que fue una de las primeras realizadas en un yacimiento arqueológico en la Comunidad de Madrid (Rascón, 2000), consiste en un edificio techado en el que, a través de pasarelas en un nivel superior, se obtiene una perspectiva en altura de los muros, patios, arcos, mosaicos, etc., y demás elementos presentes en la casa.

A lo largo de esta pasarela, en una serie de puntos singulares, encontramos una relación de paneles que hacen referencia a las estructuras que se encuentran inmediatamente frente al punto de vista del observador. Estos paneles contienen unos elementos que se repiten en todos ellos. Por un lado, una explicación que hace referencia a la funcionalidad que tenía en época romana la estructura o zona que se está estudiando (termas, patio, jardín, etc.), así como referencias al proceso de excavación, los materiales encontrados, las interpretaciones llevadas a cabo en función de estos descubrimientos, etc., acompañándose en ocasiones de documentación fotográfica. Es muy interesante que la musealización de un yacimiento apueste por explicitar y explicar la labor del arqueólogo, así como el proceso de investigación que lleva a las interpretaciones que luego se muestran al visitante y/o estudiante. De este modo -y especialmente útil si lo que estamos buscando es una funcionalidad didáctica de los yacimientos-, se traza una línea lógica entre la narración del pasado que hace la musealización y el proceso de investigación arqueológico en el que se basa; dota de sentido a esta narración y pone en valor la labor de la ciencia arqueológica (Rascón, 2007).

Sin embargo, para el tema que nos atañe, lo especialmente relevante de la cartelería es la inclusión de las estructuras que el visitante está viendo a través de modelos reconstruidos tridimensionalmente. El objetivo de estas reconstrucciones es facilitar la comprensión de la morfología y de la función de las diferentes partes del recinto en época romana, y de las que hoy en día se conservan elementos incompletos, como muros, arcos, cimientos, etc. En el caso de la Casa de Hippolytus, esta reconstrucción virtual se hace en dos fases. A cada una de estas fases le corresponde una imagen presente en la cartelería. En la primera de ellas (véase figura 1), a una foto del estado actual del yacimiento (desde la perspectiva que tiene el visitante que está en la plataforma), se superpone un esquema tridimensional muy sencillo, formado por líneas simples, que reconstruye volumétricamente el espacio, completando muros, puertas, ventanas, añadien-
Lo especialmente relevante de la cartelería es la inclusión de las estructuras que el visitante está viendo a través de modelos reconstruidos tridimensionalmente. El objetivo de estas reconstrucciones es facilitar la comprensión de la morfología y de la función de las diferentes partes del recinto en época romana, y de las que hoy en día se conservan elementos incompletos, como muros, arcos, cimientos, etc. 
do techumbres, elementos arbóreos, de decoración, alguna figura humana que sirve para comprender los tamaños de las estructuras, etc. De este modo, el visitante puede comparar con facilidad, y a la vez, los restos que está observando con la reconstrucción virtual presente en el panel.

Una vez que se ha llevado a cabo esta primera reconstrucción, donde el objetivo es que el visitante tome conciencia general sobre tamaños, volumetría, estructuras desaparecidas y presentes, así como sobre la morfología general de la zona que está observando, se procede a una reconstrucción digital con más detalle (véase figura 2). Para realizar esta segunda reconstrucción se toman como base las líneas esquemáticas de la primera imagen, pero completando esta con colores, texturas, elementos decorativos más precisos, que aportan más datos sobre la función que tenían dichos espacios, con personajes humanos que llevan a cabo actividades, etc. Esta segunda reconstrucción, por lo tanto, complementa a la primera, otorga una información extra, resulta más atractiva al incluir colores, texturas, escenas de la vida cotidiana, y acaba por facilitar una comprensión más completa de la zona.

Figura 2. Yacimiento arqueológico Casa de Hippolytus

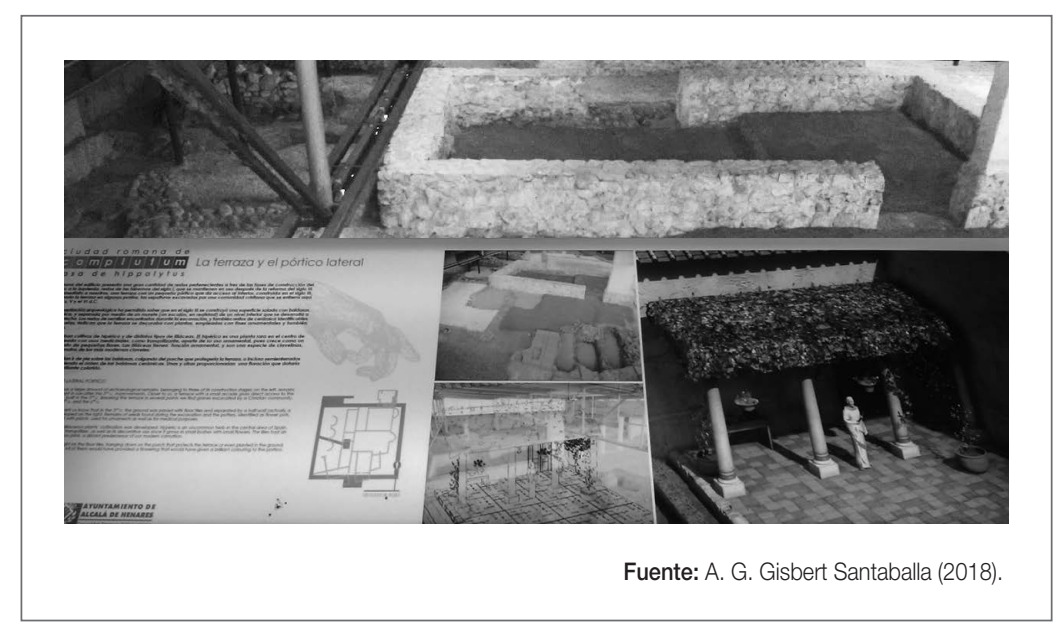




\subsection{Vídeos como presentación previa. Puerto Fluvial de Caesaraugusta (Zaragoza)}

Otra forma de incorporar las nuevas tecnologías y elementos audiovisuales a la difusión y explicación del patrimonio arqueológico es la utilización de vídeos como soporte explicativo del yacimiento.

En este sentido, los vídeos o las proyecciones introductorias ligadas a la difusión del patrimonio son cada vez más comunes en museos de tipo histórico y arqueológico. Podemos encontrar ejemplos de estos vídeos, de tipo narrativo y explicativo, en lugares como el Museo Arqueológico Nacional de Madrid (MAN) o en el yacimiento arqueológico Gadir (Cádiz) (Gener, 2015). La función que caracteriza a estos vídeos o proyecciones es la de introducir al visitante, a través de una narración que incorpora elementos visuales y de sonido, en el contexto histórico, económico, social o artístico de las piezas o colecciones visitadas. Es el caso que podemos encontrar en el Museo del Puerto Fluvial de Caesaraugusta, en Zaragoza.

Al igual que ocurre con otros yacimientos romanos de la península, los restos de la antigua Caesaraugusta se encuentran bajo construcciones, edificios y plazas de la actual ciudad de Zaragoza. La excavación de la parte noroeste del foro, entre 1990-1991, reveló los restos de un gran edificio de doble altura, con arcos, paralelo al río Ebro, y conectado a él por unas escalinatas. Los restos fueron interpretados como pertenecientes al puerto fluvial de época romana, muy importante por ser el centro de redistribución de mercancías provenientes del interior de la península ibérica y del Mediterráneo, a través del río Ebro (Erice, 2011).

En el interior del museo, junto a los restos de la cimentación del edificio y de las escalinatas de acceso, encontramos una maqueta de madera a escala reducida que reconstruye el edificio, carteles explicativos, ánforas y otros elementos asociados al comercio fluvial y marítimo (Huerta, 2015). Lo que aumenta la comprensión del yacimiento, sin embargo, es el vídeo que se expone al comenzar

La función que caracteriza a estos vídeos o proyecciones es la de introducir al visitante, a través de una narración que incorpora elementos visuales y de sonido, en el contexto histórico, económico, social o artístico de las piezas o colecciones visitadas la visita. A través de una proyección en una sala especialmente dedicada a ello, se nos presenta una narración que incluye animaciones, mapas, dibujos animados, fotografías, etc., usando el hilo conductor de un comerciante romano ficticio y un supuesto viaje de ida y vuelta, contado en primera persona, desde la ciudad de Caesaraugusta hasta la desembocadura del río Ebro. De este modo, se explican aspectos como los diferentes productos del interior peninsular 
(hierro de las minas del Moncayo, madera de los bosques pirenaicos, etc.), así como los que remontan el río Ebro, provenientes de otras provincias del Imperio romano. Elementos como las transacciones comerciales, el sistema de redistribución e intercambios comerciales romanos, así como técnicas de navegación fluvial también son explicados a través del citado vídeo (véase figura 3).

Figura 3. Puerto Fluvial de Caesaraugusta

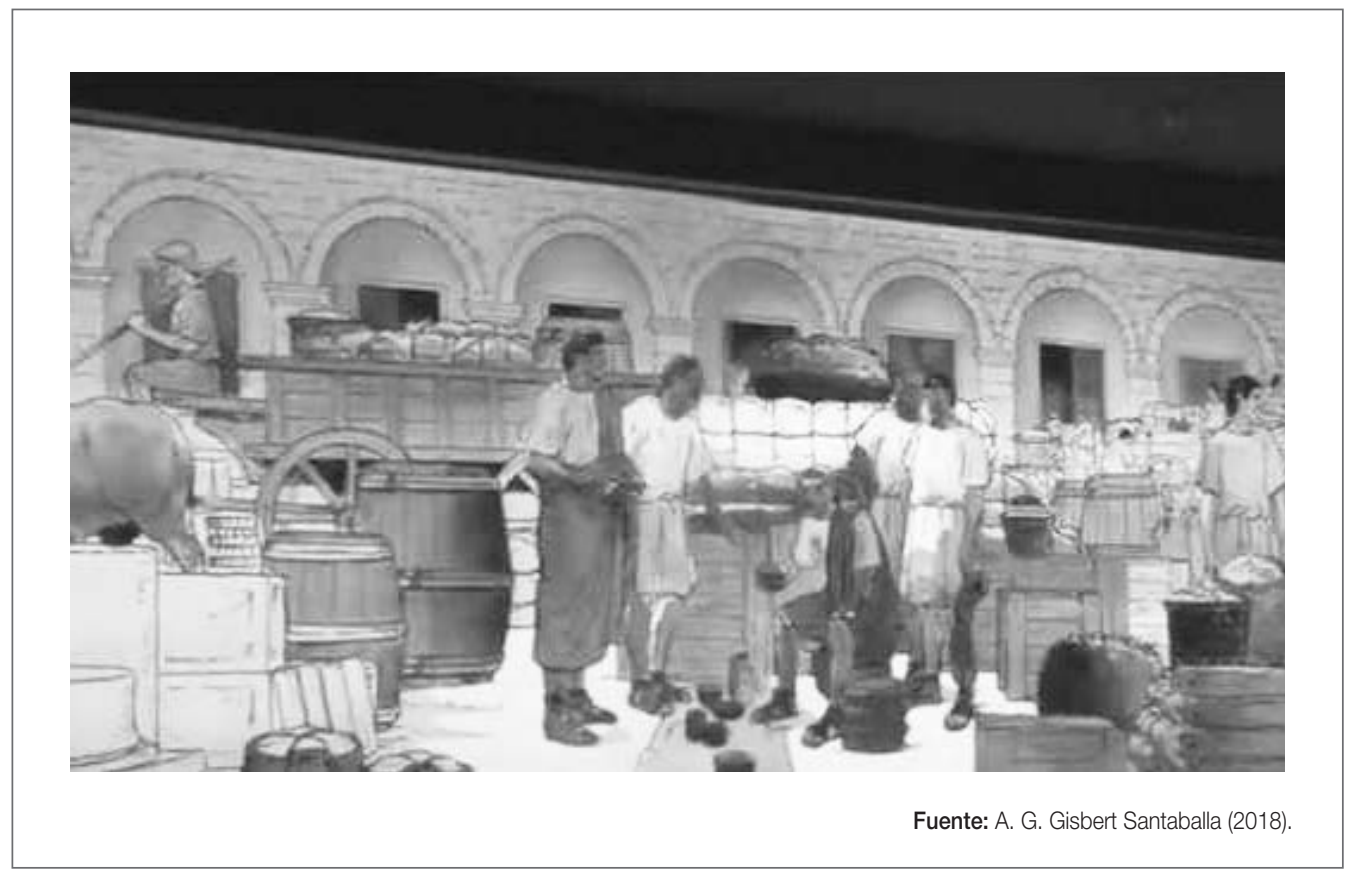

Tras la proyección principal, se levanta la pantalla protectora, que, a su vez, cubre la entrada a la parte del yacimiento y museo. Al introducirse en el mismo, se activa una nueva proyección, que, esta vez, contextualiza a los personajes ya introducidos por el vídeo sobre los elementos musealizados, como los restos de las escalinatas o las réplicas cerámicas.

\subsection{Reconstrucción en 3D de la Tumba Regolini-Galassi (Italia). Proyecto Etruscanning}

En el caso del proyecto Etruscanning, el objetivo que se persigue es la reconstrucción virtual de un contexto funerario, las tumbas etruscas de Regolini-Galassi en Cerveteri (norte del Lacio, Italia), que presentan unas características muy comunes en yacimientos arqueológicos de todo el mundo. 
Por un lado, los objetos encontrados en la excavación, los ajuares funerarios, se encuentran exhibidos y conservados en museos. Aunque es una práctica común en muchos yacimientos -al asegurar mejor la conservación de dichos objetos-, separarlos del lugar donde se encontraron provoca una descontextualización y una difícil comprensión de los mismos. Por otro lado, las tumbas, y otras estructuras, presentan problemas de accesibilidad y conservación, y su acceso por parte del público no siempre es posible. Esta circunstancia también es compartida por yacimientos arqueológicos a lo largo del mundo, que permanecen cerrados e inaccesibles al público en la actualidad.

Es en estas circunstancias cuando una recreación virtual de la tumba y de los objetos encontrados en ella cobra sentido y tiene una gran importancia. De este modo, con la recreación virtual, los visitantes, en su visita al museo, pueden tener una experiencia inmersiva e interactiva, viendo los objetos expuestos en la disposición y en el contexto adecuados, facilitando su comprensión del mundo ritual y funerario, en este caso etrusco, y pudiendo obtener información escrita, sonora y visual sobre el yacimiento en cuestión.

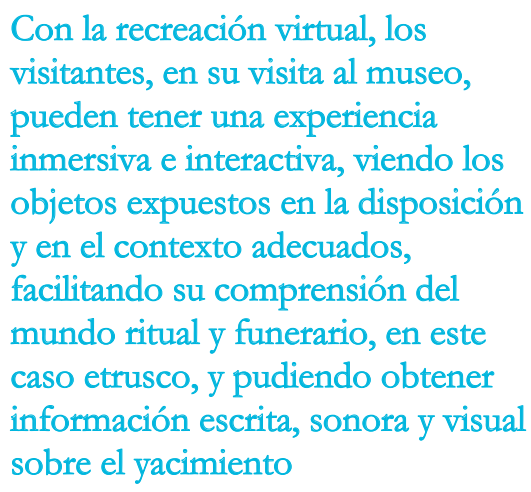

Con la recreación virtual, los visitantes, en su visita al museo, pueden tener una experiencia inmersiva e interactiva, viendo los objetos expuestos en la disposición y en el contexto adecuados, facilitando su comprensión del mundo ritual y funerario, en este caso etrusco, y pudiendo obtener información escrita, sonora y visual sobre el yacimiento

En cuanto al proceso de elaboración del proyecto, este se llevó a cabo entre los años 2011-2013, mediante fondos europeos, por un consorcio de empresas, institutos, universidades y museos de Italia, los Países Bajos y el Estado Vaticano. Entre ellas, destacan la Universidad de Ámsterdam, el Instituto de Tecnologías Aplicadas al Patrimonio Cultural de Italia o los Museos Vaticanos.

El primer paso consistió en la formulación de hipótesis acerca de la distribución de los objetos encontrados en la tumba del siglo VII a. C. (Colonna, 1997). Descubierta en el año 1836, los ajuares funerarios fueron inmediatamente extraídos de la tumba sin documentar su distribución ni posición de forma metódica. Es significativa la socialización y difusión que se hizo de esta primera parte del proyecto a través de un blog en el que se iban compartiendo las novedades que surgían, las hipótesis y los replanteamientos con los que se trabajaba, etc.; en definitiva, un ejemplo de apertura, de transparencia y de socialización del trabajo arqueológico a través de las redes sociales.

En una segunda fase, el proyecto escaneó con técnicas láser el interior de las tumbas y digitalizó sus formas. De este modo, la simulación virtual recrea la tumba en el momento histórico correspondiente al siglo VII a.C., con sus pinturas murales, objetos, ajuares y cuerpos recién enterrados. 
La incorporación de los objetos a la tumba reconstruida implicó su digitalización en los Museos Vaticanos, donde se conservan. Al no permitirse escanear los objetos mediante láser, la técnica utilizada fue la fotogrametría (una media de 36 fotografías de cada objeto y la posterior incorporación a un software 3D), y su «restauración», una vez digitalizados, usando para ello el asesoramiento de un equipo de restauradores y conservadores.

El último paso consistió en la elaboración de un guion, de una narración y de un recorrido interactivo que permite al visitante «desplazarse» por las diferentes estancias de la tumba. Un sistema de pulsadores en el suelo reconoce los movimientos del cuerpo del visitante (véase figura 4) y la cámara se mueve en consecuencia (Pietroni, 2013). En su visita a las diferentes cámaras, el visitante va recabando información a demanda sobre los objetos desplegados en cada una de ellas. Todo ello se complementa con las voces y las narraciones de los personajes nobles enterrados en la tumba, que acompañan y guían al visitante a través de su recorrido y en su aprendizaje, hablando sobre diferentes aspectos de las creencias, de la ideología, del mundo funerario y de la cultura etrusca en general.

Figura 4. Proyecto Etruscanning 3D

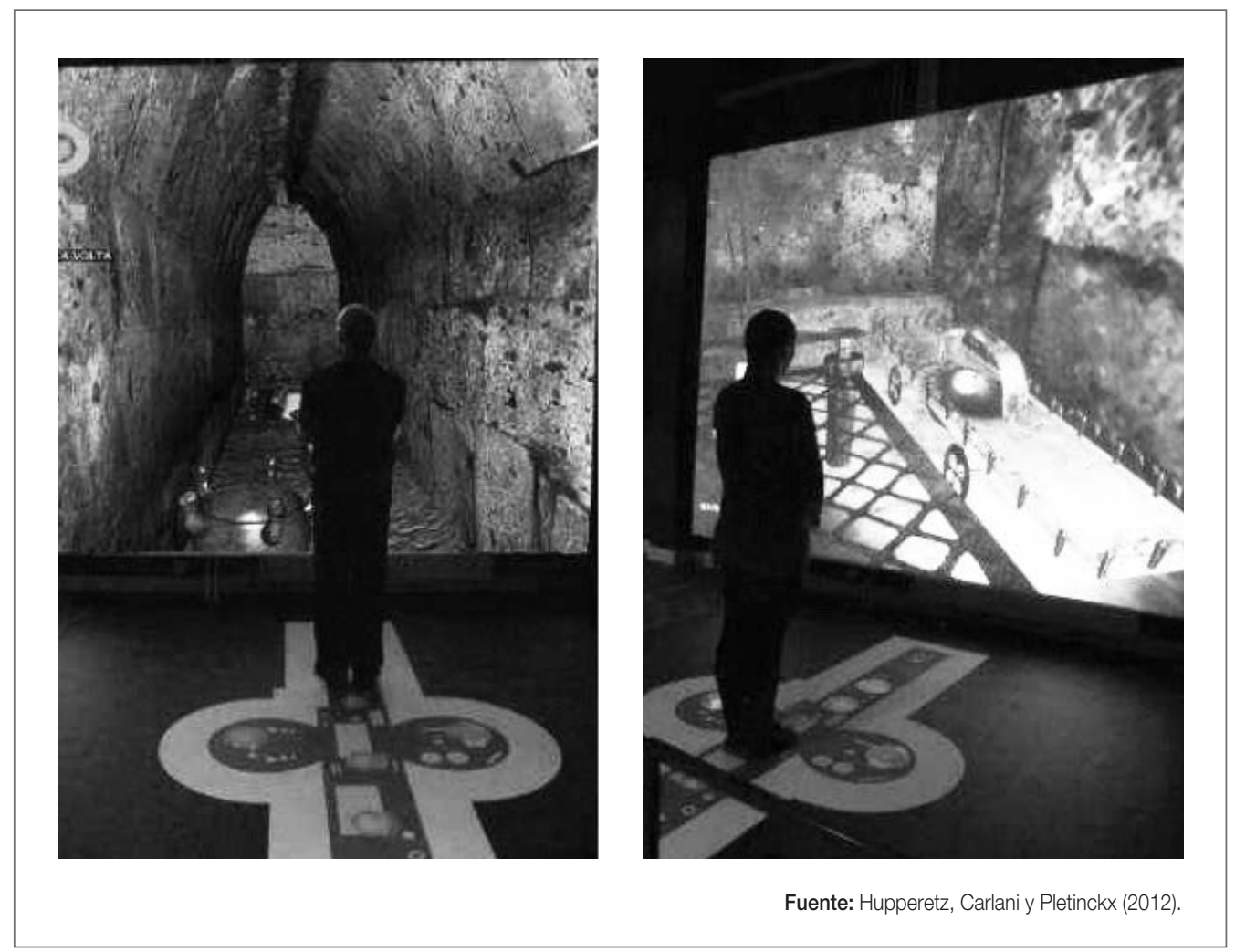




\subsection{Digitalización de espacios históricos y arqueológicos: visita virtual a la Alhambra (Granada) y a la Cueva Chauvet-Pont d'Arc (Francia)}

Siguiendo el análisis realizado a la Tumba Regolini-Galassi, analizaremos en este apartado otros ejemplos de digitalización de espacios patrimoniales históricos y arqueológicos. La principal ventaja de estos modelos radica en que permiten una visita virtual desde dispositivos informáticos, a través de la red, sin necesidad de estar presentes físicamente en el yacimiento o en el espacio concreto.

En nuestro país, encontramos gran cantidad de estas visitas virtuales, como la Lonja de la Seda (Valencia), el Parque Arqueológico de Segóbriga (Cuenca), el palacio y los jardines de la Alhambra (Granada), la catedral de Burgos, etc., y también en otros países de nuestro entorno, como la ciudad de Pompeya (Italia), cuya digitalización ha sido llevada a cabo por la empresa Google Maps, o la Cueva Chauvet-Pont d'Arc (Francia).

A pesar de la gran cantidad de ejemplos que podríamos mencionar, el grado de calidad, interactividad e información disponible en estas visitas virtuales varía enormemente de unas a otras.

De los ejemplos comentados con anterioridad, en muchos de ellos (Lonja de la Seda y catedral de Burgos) encontramos visitas que simplemente permiten un desplazamiento por diferentes estancias y lugares, con vistas de $360^{\circ}$, muy ricas visualmente, pero que no aportan información ni contextualización sobre los mismos, y que, por lo tanto, fallan en constituir lo que autores como Sancho (2008) o Albert (2014) definen como TAC.

La «virtualización» es un fin en sí mismo y no un medio para llegar a una difusión educativa del patrimonio histórico.

Dentro de los ejemplos que sí aportan información relevante sobre los espacios, encontramos también gran variabilidad, que mostraremos brevemente en los casos de la visita virtual al palacio y a los jardines de la Alhambra (Granada) y a la Cueva Chauvet-Pont d'Arc (Francia).

En el primer caso, la visita virtual a la Alhambra, desarrollada por la Universidad de Granada, nos ofrece, más que un recorrido virtual, una serie de fotografías e información sobre diferentes espacios del conjunto, accesibles a través de un plano interactivo (véase figura 5). De este modo, el visitante virtual recorre a través de «saltos» los diferentes espacios, estructuras, salas y elementos significativos del palacio, proporcionándole, sobre cada uno de ellos, información acerca de sus usos, época, evolución, materiales, modificaciones, interpretación histórica, etc. 
Figura 5. Capturas de pantalla del tour virtual de la Alhambra

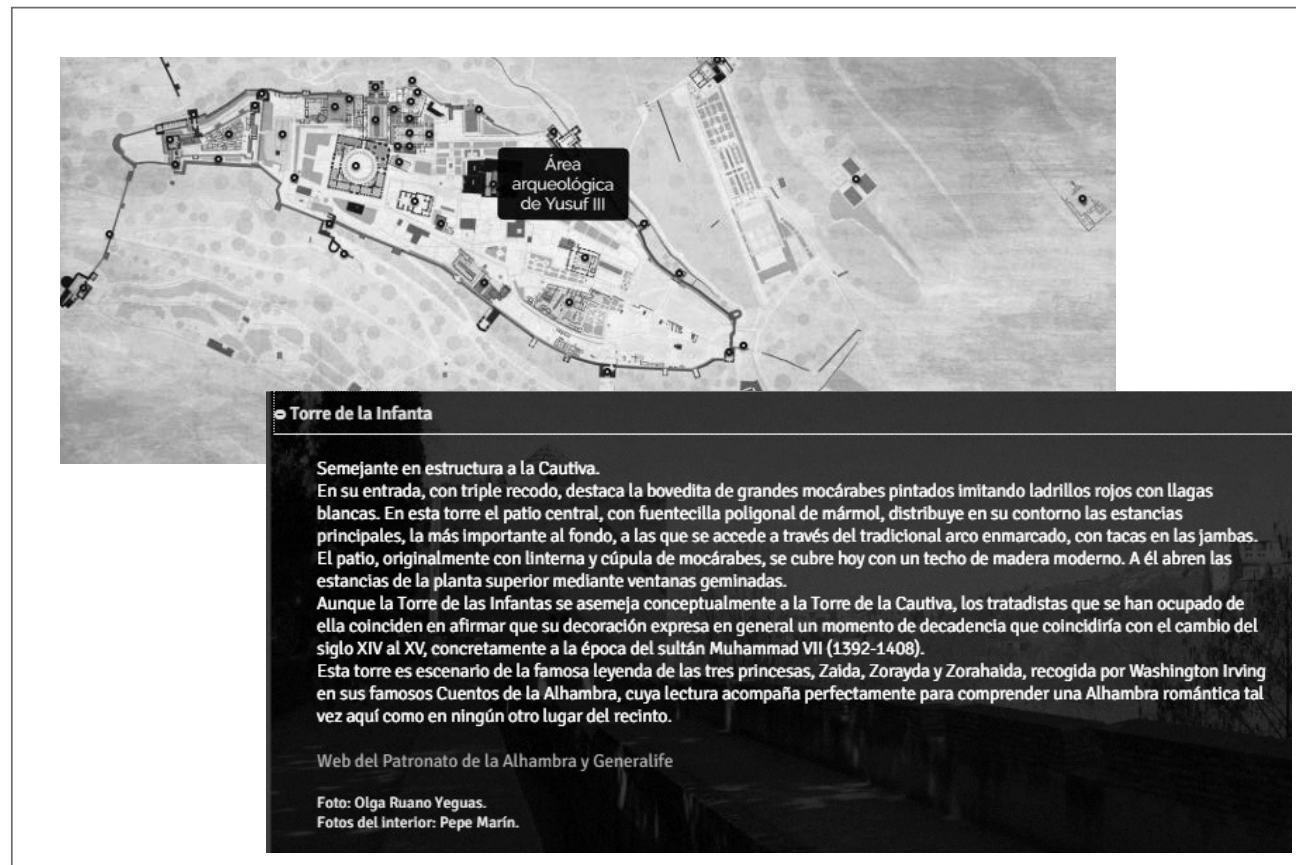

Fuente: <https://www.alhambra.org/mapa-virtual-alhambra.html>

Las limitaciones de este ejemplo son evidentes, ya que, aunque refiere gran cantidad de información sobre los diferentes espacios, esta resulta densa, poco motivadora y una copia directa de la información textual contenida en la web del Patronato de la Alhambra. Es un tipo de visita virtual que, como explica Sabbatini (2003), resulta sencilla y asequible, pero adolece de una falta de interactividad, interés y motivación para el visitante.

Un caso diferente lo encontramos en la visita virtual a la Cueva Chauvet-Pont d'Arc (Francia). La interfaz de acceso resulta muy atractiva, permitiendo al visitante una visión de $360^{\circ}$ del entorno de las diferentes salas o cuevas y su desplazamiento de una a otra. Esta visión permite el acceso a algunos elementos de dichas
En la visita virtual a la Cueva Chauvet-Pont d'Arc (Francia), la interfaz de acceso resulta muy atractiva, permitiendo al visitante una visión de $360^{\circ}$ del entorno de las diferentes salas o cuevas y su desplazamiento de una a otra. Esta información se complementa con un glosario de ciertos términos específicos, referentes a diferentes disciplinas, que aportan una explicación interdisciplinar del yacimiento y que, además, permiten al visitante no experto una comprensión adecuada y significativa de la cueva 
salas que son relevantes y que, al hacer clic sobre ellos, despliegan información adicional de las pinturas rupestres y del registro arqueológico de las salas (véase figura 6).

Esta información se complementa con un glosario de ciertos términos específicos (puntospalmares, arte parietal, azagaya, etc.), referentes a diferentes disciplinas (botánica, arqueología, antropología, etc.), que aportan una explicación interdisciplinar del yacimiento y que, además, permiten al visitante no experto una comprensión adecuada y significativa de la cueva.

Figura 6. Captura de pantalla del tour virtual de la Cueva Chauvet-Pont d'Arc

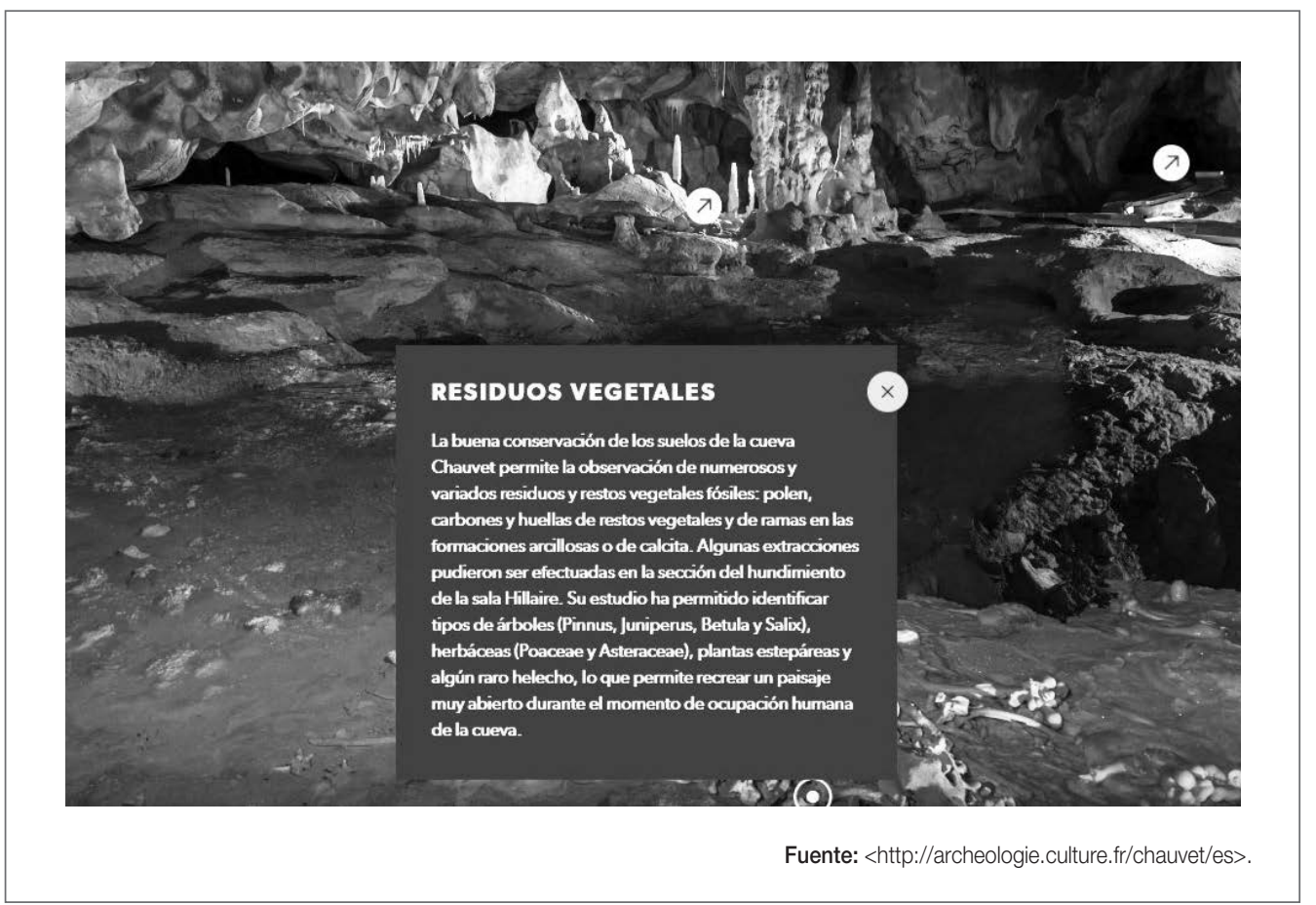

El caso de Chauvet-Pont d'Arc reúne, por lo tanto, dos de los requisitos más importantes para entornos virtuales enumerados por Bellido (2001), que son posibilidad de inmersión e interactividad, así como una de las grandes ventajas señaladas por Ortiz (2011) para el uso de la nuevas tecnologías en los procesos educativos, como es la interdisciplinariedad.

\subsection{Vídeo mapping. Sant Climent de Taüll (Lleida)}

Otra de las técnicas que puede aplicarse con éxito a la difusión y puesta en valor del patrimonio es el vídeo mapping. Dicha técnica consiste en la proyección de diferentes ele- 
mentos (contenido audiovisual, texturas, animaciones en 3D, etc.), diseñada a medida, sobre estructuras, elementos volumétricos o relieves, utilizando proyectores de vídeo digital (Alonso y Gárciga, 2013).

Los ejemplos de esta técnica aplicados al patrimonio son varios. Destaca en nuestro país el de la iglesia románica de Sant Climent de Taüll, en Lleida. Los frescos y las pinturas murales de su bóveda fueron trasladados al Museo Nacional de Arte de Cataluña en el primer tercio del siglo XX (Cuadrado, 2012), y, desde 1955, la iglesia mostraba una reproducción de las pinturas realizada en yeso. En el año 2013 se inicia un proyecto mediante el cual la reproducción en yeso es retirada, dejando al descubierto restos de la pintura original.

Es en este momento cuando, con la colaboración de empresas como Burzon Comenge, Charmex o Base 2, se plantea llevar a cabo una producción de vídeo mapping permanente (Mateos y Gifreu-Castells, 2014) que proyecte sobre el ábside de la iglesia los frescos reconstruidos digitalmente. Para ello, se inicia un proceso en el que, una vez retirada la copia de yeso y restauradas las capas y los restos de pintura profunda, se lleva a cabo un escáner láser de la iglesia.

De forma paralela, en el Museo Nacional de Arte de Cataluña, se digitalizaron y analizaron las pinturas originales conservadas. Los resultados de este estudio en cuanto a color, trazos, posición espacial, etc., permitieron la restauración y reconstrucción digital de las pinturas: restitución de colores donde se habían perdido, de dibujos y formas que no se habían conservado, siguiendo las hipótesis de los investigadores, hasta la reconstrucción completa del conjunto.

Una vez hecho esto, se procedió a la instalación de seis proyectores repartidos por la iglesia, con los que se ajustó la reconstrucción digital del paso anterior a las paredes y dimensiones de la bóveda. Finalmente, se introdujeron una serie de animaciones mediante las que los distintos elementos y personajes de la pintura iban apareciendo. Junto a estos efectos, se compuso una banda sonora que sería integrada a las animaciones mediante un sistema de sonido desplegado en la iglesia.

El resultado final es muy satisfactorio. Siguiendo los requisitos establecido por Bellido, nos encontramos ante un entorno virtual altamente inmersivo, donde la conjunción de imágenes, animaciones y música dan lugar a una reconstrucción de los frescos muy original y enriquecedora, sensorialmente estimulante, atractiva y motivadora.
Otra de las técnicas que puede aplicarse con éxito a la difusión y puesta en valor del patrimonio es el vídeo mapping. Siguiendo los requisitos establecido por Bellido, nos encontramos ante un entorno virtual altamente inmersivo, donde la conjunción de imágenes, animaciones y música dan lugar a una reconstrucción de los frescos muy original y enriquecedora, sensorialmente estimulante, atractiva y motivadora 
En la figura 7 podemos observar el aspecto de la iglesia con los proyectores apagados, y en la figura 8, con los proyectores encendidos.

Figuras 7. Captura de pantalla del vídeo «Making off \#taull1123. Procés del mapping». Proyectores apagados

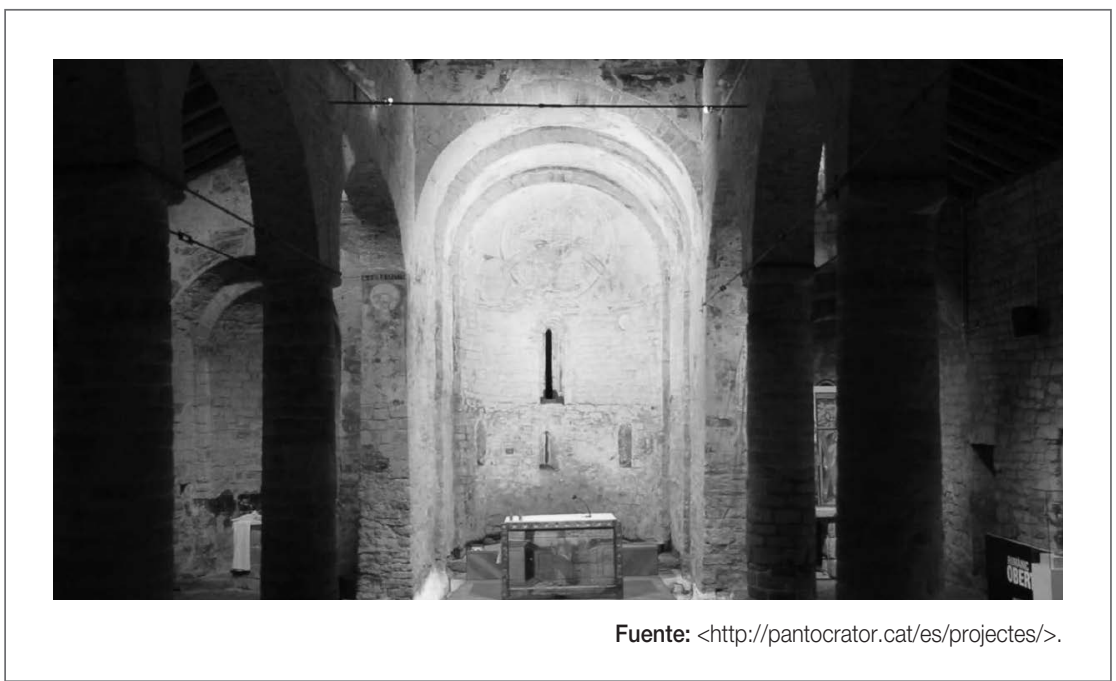

Figuras 8. Captura de pantalla del vídeo «Making off \#taull1123. Procés del mapping». Proyectores encendidos

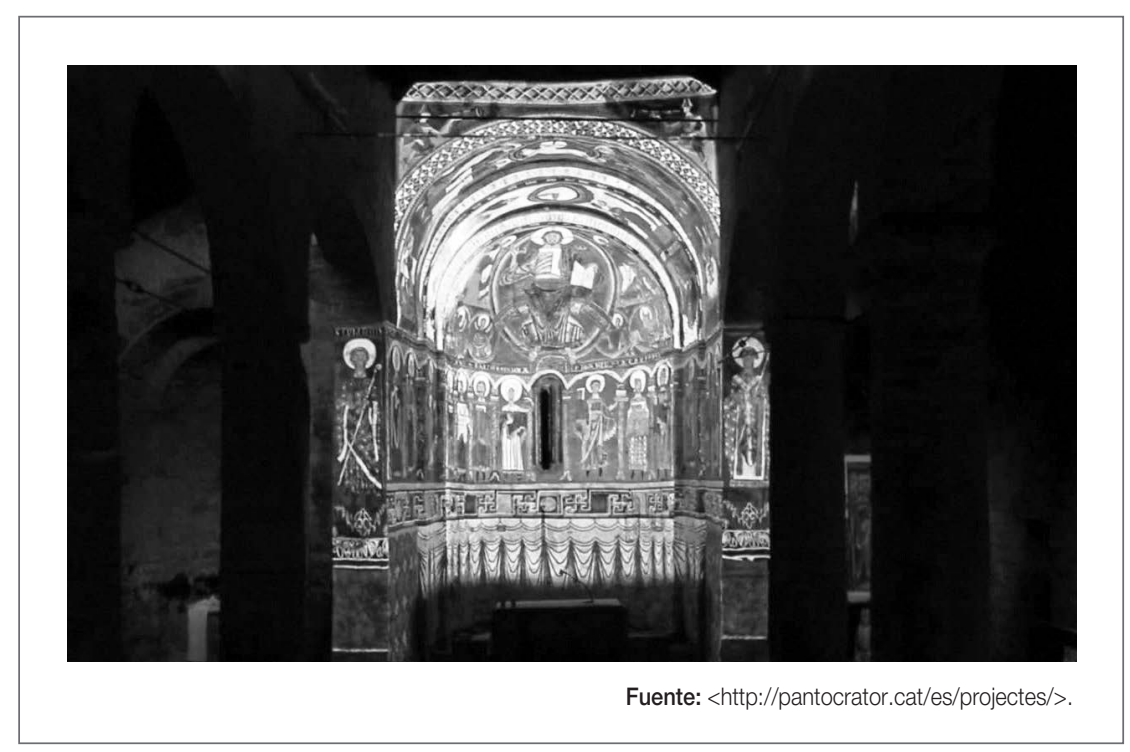




\subsection{Gafas de realidad virtual. Past View (Sevilla)}

La última de las tecnologías aplicadas al patrimonio que trataremos en este trabajo son las gafas de realidad virtual utilizadas por la empresa Past View durante sus rutas turísticas por Sevilla. La empresa Past View nace en Sevilla en el año 2012, formada por un grupo interdisciplinar que reúne a programadores, informáticos, historiadores, historiadores del arte, etc., y en la actualidad organiza rutas turísticas con contenido histórico, basadas en gafas de realidad virtual, en las ciudades de Sevilla y Éfeso (Turquía), planeando su expansión en el futuro a otras ciudades como Barcelona o Santiago de Compostela. El dispositivo de realidad virtual consiste en unas gafas que se conectan con un cable a una pequeña terminal informática, del tamaño de un teléfono móvil (touch pad). A estos dos dispositivos habría que añadir unos auriculares, necesarios para escuchar ciertos vídeos y narraciones. La visita tiene una duración total de dos horas y sigue una estructura fija. Un paseo por la ciudad de Sevilla, conducido por un guía, y durante el cual se hacen una serie de paradas establecidas en puntos significativos de la ciudad. En estas paradas se lleva a cabo una explicación previa por parte del guía y, a continuación, se pide a los visitantes que se pongan las gafas, reproduciéndose de este modo los contenidos relacionados con cada lugar.

Las secuencias se inician normalmente con un fragmento de vídeo, consistente en la recreación histórica del lugar a manos de un personaje. Este personaje, un actor caracterizado de forma diferente dependiendo de la época, se dirige al visitante para hablarle sobre aspectos y contenidos relacionados con la época histórica tratada y con el espacio en el que se encuentran. A su espalda, se puede observar la reconstrucción histórica del espacio y se ven otros personajes secundarios que animan, ambientan el vídeo e interactúan con el narrador (véase figura 9).

Figura 9. Captura de pantalla de la web de la empresa Past View

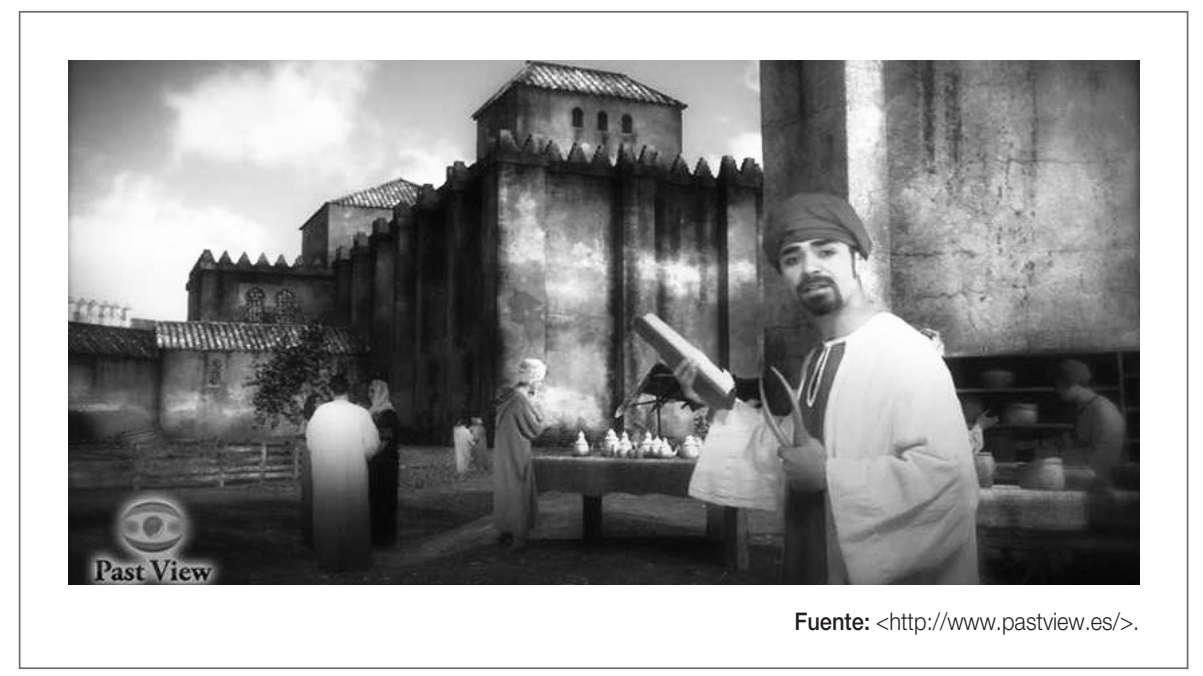


El guion de los personajes aborda diferentes aspectos de la política, la sociedad y la economía de la época, no de forma intensiva, sino a través de lo que su discurso y sus interacciones con otros personajes van creando.Como ejemplo, encontramos, en la Plaza de San Francisco, a un escribano de los siglos XVI-XVII que nos habla acerca de su trabajo. A través de su narración se pone de manifiesto la situación de Sevilla como centro del comercio con América, las profesiones surgidas en torno a él, las guerras de Flandes, la corrupción de cargos públicos, etc. Se introducen, además, ciertos edificios a través de personajes famosos, como Miguel de Cervantes, un interesante recurso que permite atraer la atención del espectador y relacionar la historia de los espacios y de los edificios con personajes fácilmente identificables e interpretables.

Tras las recreaciones, suele ser reproducido un vídeo en el que se analizan más en detalle las características de los edificios a los que se ha hecho referencia en la recreación anterior. Se tratan, en forma de audio y texto, junto a una reconstrucción virtual del edificio, aspectos como el año de construcción, el arquitecto y la duración de la obra, el estilo, la función, su morfología y evolución, etc. Los vídeos se sitúan, por lo tanto, en la línea de las tradicionales audioguías turísticas, aunque con valiosos elementos visuales, como las reconstrucciones virtuales, que enriquecen la experiencia.

El último de los contenidos, que suele seguir a estos vídeos, es la realidad aumentada (Ruiz, 2011). En esta, aunque no se dispone de sonido ni de narración alguna, el visitante puede llevar a cabo un recorrido visual en torno suyo. Las gafas responden a los movimientos de cabeza del visitante y le permiten observar la reconstrucción histórica del espacio en el que se encuentra, que corresponde a la época en la que ha tenido lugar la recreación con

Resulta especialmente interesante apreciar las diferencias que en cuanto a morfología y evolución de los espacios nos ofrecen las gafas, superando las tradicionales explicaciones de los guías de patrimonio, que constantemente apelan a la «imaginación» del visitante y a su capacidad de reconstruir mentalmente estructuras ya desaparecidas o modificadas el actor que hemos explicado al principio. Resulta especialmente interesante apreciar las diferencias que en cuanto a morfología y evolución de los espacios nos ofrecen las gafas, superando las tradicionales explicaciones de los guías de patrimonio, que constantemente apelan a la «imaginación» del visitante y a su capacidad de reconstruir mentalmente estructuras ya desaparecidas o modificadas. Nos encontramos, por lo tanto, ante una serie de ventajas educativas asociadas a la realidad virtual y relacionadas con la motivación de los alumnos y con una mejor comprensión de los contenidos históricos y artísticos (Leiva y Moreno, 2015). 


\section{Discusión y conclusiones}

\subsection{Discusión}

Una vez descritos los cinco ejemplos, en este apartado nos centraremos en discutir brevemente las ventajas e inconvenientes, en cuanto a efectividad educativa, que encontramos en cada uno de ellos.

El yacimiento de la Casa de Hippolytus revela una clara vocación didáctica, al incluir en su cartelería, junto a una explicación más técnica o «avanzada», imágenes sencillas de reconstrucción virtual y una adecuación de los itinerarios de la visita, atendiendo a diferentes edades, gustos e intereses, con el objetivo final de ser un yacimiento accesible a una gran variedad de público. Sin embargo, la mera inclusión de modelos virtuales en cartelería no es suficiente para obtener resultados satisfactorios en cuanto a inmersión e interactividad, y estaríamos muy en la línea de los museos tradicionales (Kotler y Kotler, 2001).

Vídeos introductorios y explicativos como el del Puerto Fluvial de Caesaraugusta acaban por favorecer la inmersión del visitante en los conceptos de tipo histórico asociados al yacimiento arqueológico en cuestión y lo predisponen hacia una mejor comprensión de los restos que está visitando. Sin embargo, este tipo de instalaciones siguen siendo limitadas en el sentido de que no ofrecen al visitante un entorno tridimensional ni interactivo, sino meramente pasivo.

Un caso diferente es el de la reconstrucción virtual de la Tumba Regolini-Galassi. La reconstrucción digital $3 \mathrm{D}$ de la tumba no es solo una réplica digital de la misma. La utilización de la realidad virtual implica un contexto inmersivo e interactivo dentro del cual el visitante entra en contacto con la cultura, la simbología y la mente etruscas. Esto se hace posible al poder integrar en el espacio de realidad virtual una gran cantidad de información, relativa al mundo etrusco, proveniente de otras tumbas, yacimientos e investigaciones. De este modo, la visita a los objetos en la tumba trasciende lo particular y local de la misma, y el sistema de realidad virtual se convierte en un medio de comunicación y de aprendizaje significativo relativo a todo el mundo etrusco. De forma similar, la interfaz e información contenidas en la visita virtual a la Cueva de Chauvet, aparte de facilitar el acceso a este tipo de yacimientos a través de la red sin necesidad de acudir a los mismos, es utilizado para dotar a la interpretación y difusión de los restos arqueológicos de una visión interdisciplinar, que aumenta el interés y el valor educativo de dichos yacimientos.

El caso de Sant Climent de Taüll y su vídeo mapping se revela, por su parte, como una técnica de reconstrucción virtual muy rica y versátil, en la cual se pueden integrar elementos animados, sonoros, de música y narración, que lo convierten en una herramienta educativa de primer orden. Las limitaciones de esta técnica, sin embargo, vendrían dadas por el lugar donde puede llevarse a cabo. Prácticamente, el uso de proyectores restringe su 
uso a lugares cerrados y oscuros, o a proyecciones llevadas a cabo durante la noche. Necesitamos, además, superficies amplias y completas, uniformes y no destruidas, sobre las que poder proyectar los modelos creados.

Por último, los contenidos de las gafas desarrolladas por la empresa Past View ofrecen una experiencia de arqueología virtual altamente inmersiva (aunque quizás echamos en falta algo más de interactividad por parte del visitante, como en la Tumba Regolini-Galassi) y que aumenta la motivación del usuario a la hora de acercarse a un conocimiento del pasado histórico.

\subsection{Conclusiones}

Una vez analizados diferentes métodos para difundir el patrimonio histórico-arqueológico a través de las nuevas tecnologías, pasamos a discutir y sacar conclusiones acerca de su efectividad a la hora de aumentar el interés y la motivación de los alumnos de secundaria y bachillerato.

La configuración de los yacimientos arqueológicos actuales se basa en la fosilización del espacio (Santacana y Masriera, 2012), es decir, en la creación de un paisaje de ruinas, un paisaje donde se intenta detener el tiempo, donde se reconstruyen ciertos muros, columnas, etc., pero donde la ruina es el factor fundamental. En torno a estas ruinas se articulan una serie de infraestructuras encaminadas a facilitar su visita por parte del público. Consisten en plataformas de acceso, paneles informativos, gráficos, etc., que recogen las hipótesis e interpretaciones de los arqueólogos y expertos acerca de los restos.

El principal argumento que guía este tipo de intervenciones es el hecho de que, manteniendo la ruina, se está conservando la fuente primaria, los datos, no modificados por hipótesis de otros, que permiten al visitante sacar e inferir sus propias conclusiones del pasado. En el núcleo de este argumento se sitúan las ideas de Ruskin (1849), teórico clásico del patrimonio, que defiende el principio empírico de que los datos son el único garante de la verdad. De este modo, los datos «objetivos», esto es, no interpretados ni modificados, serían, en el caso de los yacimientos arqueológicos, las ruinas y los restos encontrados. Se rechaza la reconstrucción o la restauración de dichos restos al entender que «falsean» los datos arqueológicos y las fuentes primarias encontradas, ya que dichas restauraciones/ reconstrucciones se realizan desde una perspectiva actual, con unas técnicas, ideologías, hipótesis, etc., que no estaban presentes en la época de la que proviene la ruina.

El resultado de esta concepción son lugares desnudos, despojados de objetos (se consignan en los museos), carentes de vegetación, estériles, sin vida, aburridos y yermos, sin capacidad de sorprender, de motivar ni de excitar la curiosidad y las ganas de aprender del visitante. Dicho de otra forma, no se contempla el patrimonio arqueológico como una forma de acceder a un conocimiento del pasado histórico a través de la cultura material, sino como un museo. Un espacio estático, cuya voluntad es la exposición de piedras y ruinas, y para cuya compren- 
sión se requieren unos conocimientos medios o avanzados de multitud de disciplinas: historia, historia del arte, competencia volumétrica y espacial, nociones de arquitectura, etc. Son, por lo tanto, espacios para personas iniciadas en la materia, que ya poseen un interés y unos conocimientos acerca del pasado histórico; algo que a priori nuestros alumnos de secundaria y bachillerato no van a poseer, y que les llevará a una falta de comprensión y motivación.

Sin embargo, la arqueología virtual, como hemos visto, nos ayuda a crear otra concepción del yacimiento. Los ejemplos vistos transforman estos espacios en centros de difusión y educación activos, dinámicos y abiertos, que no se conforman con «recibir» al público interesado por el conocimiento que de él se desprende, sino cuya voluntad es «atraer», motivar, seducir al público que a priori no está interesado por el tema. Es decir, la educación patrimonial entendida como un proceso de comunicación efectivo y adecuado entre el yacimiento y el visitante (Hernández, 2011). Se trata de una función social importantísima (Cuenca, 2013) y que contribuye al desarrollo de competencias ciudadanas fundamentales, como son el cuidado y la protección del patrimonio (Ávila y Duarte, 2012), la articulación y la configuración de identidades, y la conciencia sobre el pasado histórico y los problemas presentes y futuros (Estepa, 2013). El conocimiento del pasado histórico entendido no como una opción a la que acercarse, dependiendo de los intereses individuales de cada uno, sino como un deber, para conseguir una sociedad democrática consciente y competente; conocimiento al que se debe dotar del mayor número posible de elementos atrayentes y motivantes, que permitan a la sociedad acercarse con facilidad al mismo (Falk y Dierking, 2000).

La arqueología virtual resulta motivadora, por lo tanto, en la medida en que va a facilitar la comprensión y la inteligibilidad de los yacimientos arqueológicos como restos del pasado histórico, de una forma democrática y accesible para todos. Las técnicas reconstructivas a través de medios informáticos y la narración creada en torno a los mismo ayudan a los procesos de comprensión del espacio que se está visitando (volumetrías de los edificios, mosaicos y decoración no presente y perdida, usos y función de los mismos, actividades económicas y sociales desarrolladas, ritos, cultura, etc.). En definitiva, ayudan a presentar de formar nítida y didáctica la función de diferentes estructuras cuando aún estaban en uso, así como la sociedad y la época que los crearon y usaron. Una comprensión del pasado histórico que redunda, en definitiva, en una mayor motivación e interés hacia la materia. Por otro lado, el cuidado de la narrativa y el guion a la hora de llevar a cabo estas reconstrucciones virtuales debe tener como objetivo principal emocionar al público a través de una narración vívida, que favorecerá el aprendizaje al poner en marcha mecanismos sensoriomotores y simbólico-reconstructivos (Asencio y Pol, 2012; Acaso, 2012).

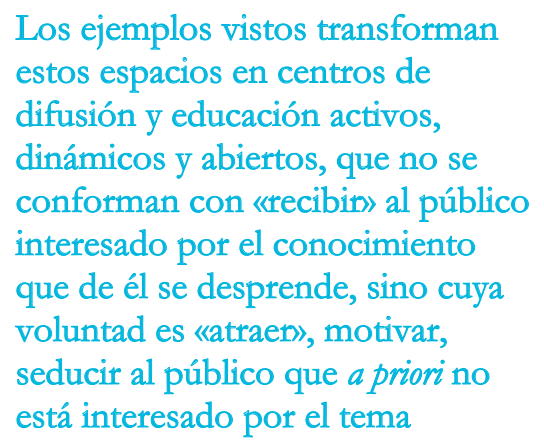

Los ejemplos vistos transforman estos espacios en centros de difusión y educación activos, dinámicos y abiertos, que no se conforman con «recibin» al público interesado por el conocimiento que de él se desprende, sino cuya voluntad es «atraen», motivar, seducir al público que a priori no está interesado por el tema 
Es importante incidir, por último, en la importancia de que la arqueología virtual no se quede en la mera réplica digital de tumbas, foros, edificios, etc. La utilización de la realidad virtual implica un contexto inmersivo e interactivo dentro del cual el visitante entra en contacto con la cultura, con la simbología y con la mente de las sociedades pasadas. Esto se hace posible al poder integrar en el espacio de realidad virtual una gran cantidad de información, proveniente de otras fuentes, yacimientos e investigaciones, en lo que los autores han venido a llamar «patrimonio virtual» o «patrimonio digital» (Carreras y Munilla, 2005; Hupperetz et al., 2012). De este modo, la visita a un yacimiento debe trascender lo particular y lo local del mismo, y el sistema de realidad virtual debe convertirlo en un medio de comunicación y de aprendizaje significativo, relativo al conjunto de la sociedad y de la época en la que se sitúan los restos arqueológicos. Una fuente de conocimiento para nuestros alumnos que no solo se circunscriba a la cultura material encontrada en él, sino que aborde de forma integral elementos de simbolismo, religión, mentalidad, ideología, sociedad, economía, manifestaciones artísticas, etc., de las sociedades pasadas.

\section{Prospectiva}

El campo de la arqueología virtual aplicada a la didáctica de la Historia es un campo que presenta un gran recorrido y futuro, ya que aúna diferentes elementos innovadores, con el denominador común del uso de las nuevas tecnologías: por un lado, el uso de las nuevas tecnologías aplicadas a la educación, como herramienta de inclusión y motivación; y, por otro lado, el uso de las nuevas tecnologías a la hora de divulgar de una forma inmersiva e interactiva el patrimonio histórico y cultural de los países.

Precisamente, esta preocupación la vamos a encontrar no solo en ámbitos académicos, sino también políticos, por parte de la Administración, a la hora de intentar aunar las esferas de educación y patrimonio a través del uso de las nuevas tecnologías. En este sentido encontramos el Plan Nacional de Educación y Patrimonio. Aprobado en 2013 por el Consejo de Patrimonio Histórico, el plan incide en la idea de que una adecuada educación patrimonial tiene efectos positivos en la valorización, protección y conservación del patrimonio al concienciar e interesar a la población acerca del mismo. Entre las actuaciones concretas, encontramos la financiación de los proyectos de innovación, en los cuales se menciona específicamente el uso de las nuevas tecnologías aplicadas a una mejor comprensión y difusión del patrimonio de nuestro país.

Otro elemento que nos llevan a hablar de un prometedor futuro en este campo de la investigación educativa es la celebración, año tras año, de congresos especializados en este 
asunto, que cada vez cuentan con un mayor desarrollo y afluencia de profesionales del ámbito de la educación y del patrimonio. Destacan el IV Congreso Internacional de Educación Patrimonial, celebrado en Madrid entre el 14 y el 16 de noviembre de 2018, con una importante carga en cuanto a contenidos e investigaciones en torno a la aplicación de las nuevas tecnologías en la difusión educativa del patrimonio; o el VIII Congreso Internacional de Arqueología Virtual, celebrado en Valencia en septiembre de 2016, con temáticas educativas tales como museos y exposiciones virtuales, juegos de patrimonio cultural, entornos colaborativos, tecnologías de internet y medios sociales en arqueología, etc.

\section{Referencias bibliográficas}

Acaso, M. (2012). Pedagogías invisibles: el espacio del aula como discurso. Madrid: Ediciones Catarata.

Albert Tarragona, J. M. (2014). Las TAC en la enseñanza de las Ciencias Sociales, la Geografía y la Historia. En J. P. Blanch y A. Santiesteban Fernández (Coords.), Una mirada al pasado y un proyecto de futuro (pp. 411418). Barcelona: Servicio de Publicaciones de la Universitat Autònoma de Barcelona.

Almansa, J. y Señorán, J. M. a . (2005). La cartelería y sus niveles. Arqueoweb: Revista sobre Arqueología en Internet, 7(1).

Alonso Atienza, L. y Gárciga Romay, L. (2013). ¿Qué gigantes?, dijo Sancho Panza. Proyecciones monumentales con vídeo mapping en los bicentenarios de las independencias de las naciones latinoamericanas. ASRI: Arte y Sociedad. Revista de Investigación, 4.

Asencio, M. y Pol Méndez, E. (2002). Nuevos escenarios en educación: aprendizaje informal sobre el patrimonio, los museos y la ciudad. Argentina: Aique.

Ávila Ruiz, R. M. ${ }^{a}$ y Duarte Piña, O. (2012). Salvemos el patrimonio, patrimonio en peligro.
Una actividad para la formación docente y ciudadana. XXIII Simposio Internacional Didáctica de las Ciencias Sociales. Educar para la Participación Ciudadana en la Enseñanza de las Ciencias Sociales, 2, 471-480.

Barthes, R. (1985). The discourse of History. Comparative Criticism, 3, 7-20.

Bellido Grant, M. ${ }^{a}$ L. (2001). Arte, museos y nuevas tecnologías. Gijón: Trea.

Brown, J. S., Denning, S., Groh, K. y Prusac, L. (2004). Storytelling in Organizations: Why Storytelling is Transforming 21st Century Organziations and Management. New York: Butterworth-Heinemann.

Carreras Monfort, C. y Munilla Cabrillana, G. (2005). Patrimonio digital: un nuevo medio al servicio de las instituciones culturales. Grupo Òliba, 1999-2003. Serie Cibercultura, EDIUOC.

Colonna, G. (1997). II letto vuoto, la distribuzione del corredo, e la finestra della Tomba Regolini-Galassi. En M. Pallottino (Ed.), Etrusca et Italica: scritti in ricordo di Massimo Pallottino (pp. 131-168). Milán: Ist. Editoriali e Poligrafici. 
Coma, L. (2014). Investigación en didáctica del patrimonio: la propuesta de modelos y nuevas líneas de actuación con dispositivos móviles. Actas I Congreso Internacional de Educación Patrimonial. Mirando a Europa: Estado de la Cuestión y Perspectivas de Futuro. Comunicaciones. Línea 5: Investigación en Educación Patrimonial. Madrid: Ministerio de Educación, Cultura y Ciencia, 609-621.

Cuadrado Gutiérrez, L. J. (2012). El Pantocrátor de la iglesia de San Climent de Taüll, en el valle de Boí: vicisitudes de una obra de arte «transportable». Un acercamiento a la pintura románica, en Cataluña, realizada con la técnica al fresco. Revista Atticus, 2, 29-47.

Cuenca López, J. M.ª (2013). El papel del patrimonio en los centros educativos: hacia la socialización patrimonial. Tejuelo. Didáctica de la Lengua y la Literatura, 19, 76-96.

Duby, G. (1994). Escribir la historia. Reflexiones, 25(1).

Erice, R. (2011). El puerto fluvial de Caesaragusta. En J. Arce (Ed.), Horrea d'Hispanie et de la Méditerranée romaine (pp. 143-157). Madrid: Collection de la Casa de Velázquez.

Estepa Giménez, J. (2013). La educación patrimonial en la escuela y el museo: investigación y experiencias. Huelva: Universidad de Huelva.

Falk J. y Dierking, L. (2000). Leaning from Museums: Visitor Experience and the Making of Meaning. Altamira Press.

García-Entero, V. (2004). Nueva propuesta interpretativa de la llamada Casa de Hippolytus de Complutum (Alcalá de Henares, Madrid). Archivo Español de Arqueología, 77(189-190), 143-158.

Gener, J. M. (2015). Gadir. Yacimiento arqueológico del teatro de títeres. Cádiz. El origen fenicio. Cómo se hizo. Ayuntamiento de Cádiz.
González-Monfort, N. (2011). La presencia del patrimonio cultural en los curricula de educación infantil, primaria y secundaria obligatoria en España. Patrimonio Cultural de España, 5, 59-74.

Hernández Hernández, F. (2011). El museo como espacio de comunicación. Gijón: Trea.

Hernández Cardona, F. X. y Rojo Ariza, M. ${ }^{a}$ C. (2012). Museografía didáctica e interpretación de espacios arqueológicos. Gijón: Trea.

Huerta, R. (2015). Saragossa sites: education from the city through heritage routes. Journal for Educators, Teachers and Trainers (JETT), 6, 67-79.

Hupperetz, W., Carlani, R. y Pletinckx, D. (2012). Etruscanning 3D Project. The 3D reconstruction of the Regolini Galassi Tomb as a research tool and a new approach in storytelling. Virtual Archaeology Review, 3(7), 92-96.

Husillos García, M. ${ }^{a}$ L. (2013). Aplicación de las TIC en el área de la arqueología virtual para alumnos con necesidades educativas especiales en la etapa de enseñanza secundaria obligatoria. Virtual Archaeology Review, 4(8), 95-99.

Ibáñez, A. (2014). Tendencias emergentes de integración de TIC en educación patrimonial. Educación, Clave de Futuro del Patrimonio. Fundación del Patrimonio Histórico de Castilla y León.

Kotler, N. y Kotler P. (2001). Estrategias y marketing de museos. Barcelona: Ariel.

Leiva Olivencia, J. J. y Moreno Martínez, N. M. (2015). Tecnologías de geolocalización y realidad aumentada en contextos educativos: experiencias y herramientas didácticas. Revista DIM: Didáctica, Innovación y Multimedia, 31.

Marqués Graells, P. (2013). Impacto de las TIC en educación: funciones y limitaciones. 3C TIC: Cuadernos de Desarrollo Aplicados a las TIC, 2(1). 
Mateos Rusillo, S. M. y Gifreu-Castells, A. (2014). Reconstrucción y activación del patrimonio artístico con tecnología audiovisual: experiencia de Taüll 1123. El Profesional de la Información, 23(5), 527-533.

Mudrovcic, M. I. (2005). Historia, narración y memoria: los debates actuales en Filosofía de la Historia. Madrid: Akal.

Ortiz Hernández, I. (2011). Las nuevas tecnologías y la educación. Almería: Tutorial Formación, SL.

Pietroni, E. (2013). The Etruscanning project: gesture-based interaction and user experience in the virtual reconstruction of the Regolini-Galassi Tomb. Digital Heritage International Congress (DigitalHeritage), 2, 653-660.

Prats, J. (2001). Valorar el patrimonio histórico desde la educación: factores para una mejor utilización de los bienes patrimoniales. En J. Morales, M. ${ }^{a}$ C. Bayod, R. López, J. Prats y D. Buesa, Aspectos didácticos de las ciencias sociales. Zaragoza: Universidad de Zaragoza.

Pujol, L. y Economou, M. (2009). Worth a thousand words? The usefulness of immersive virtual reality for learning in cultural heritage settings. International Journal of Architectural Computing, 7(1), 157-176.

Rascón Marqués, S. (2000). La Casa de Hippolytus y la recuperación del patrimonio arqueológico de Alcalá de Henares. Boletín de la $A N A B A D, 50(2), 203-218$.

Rascón Marqués, S. (2007). La asíl llamada casa de Hippolytus: la fundación de los Anios y la schola de una agrupación colegial de la ciudad romana de Complutum. Archivo Español de Arqueología, 80, 119-152.

Rascón Marqués, S. y Sánchez Montes, A. L. (2008). Las nuevas tecnologías aplicadas a la didáctica del patrimonio. Pulso, 31, 67-92.
Rico Cano, L. y Ávila Ruiz, R. M. ${ }^{a}$. (2003). Difusión del patrimonio y educación. El papel de los materiales curriculares. Un análisis crítico. En E. Ballesteros Arranz, C. Fernández Fernández, J. A. Molina Ruiz y P. Moreno Benito (Eds.), El patrimonio y la didáctica de las ciencias sociales (pp. 31-40). Asociación Universitaria de Profesores de Didáctica de las Ciencias Sociales.

Ruiz Torres, D. (2011). Realidad aumentada, educación y museos. Icono14, 9(2), 212-226.

Ruskin, J. (1849). The Seven Lamps of Architecture.

Sabbatini, M. (2003). Centros de ciencia y museos científicos virtuales: teoría y práctica. Teoría de la Educación en la Sociedad de la Información, 4.

Sancho Gil, J. M. ${ }^{a}$. (2008). De TIC a TAC, el difícil tránsito de una vocal. Investigación en la Escuela, 64, 19-30.

Santacana, J. y Coma, L. (Coords.) (2014). El m-learning y la educación patrimonial. Gijón: Trea.

Santacana i Mestre, J. y Martín Piñol, C. (2010). Manual de museografía interactiva. Gijón: Trea.

Santacana i Mestre, J. y Masriera Esquerra, C. (2012). La arqueología reconstructiva y el factor didáctico. Gijón: Trea.

Schmidt, M. (2012). Developing methods for understanding social behavior in a 3D virtual learning environment. Computers in Human Behavior, 28(2), 405-413.

Silva Galán, J. M. ${ }^{a}$. (2013). Aplicaciones de los códigos QR y la realidad aumentada en la enseñanza de las ciencias sociales. XXIV Simposio Internacional de Didáctica de las Ciencias Sociales. Universidad de Alcalá. 
Para los Grados en Derecho o en

Ciencias del Trabajo, Relaciones

Laborales y Recursos Humanos

- Administración y Finanzas

- Asistencia a la Dirección

- Secretariado

\section{Para los Grados en Administración y}

Dirección de Empresas o en Economía

- Administración y Finanzas

- Asistencia a la Dirección

- Comercio Internacional

- Gestión Comercial y Marketing

- Marketing y Publicidad

- Secretariado

- Transporte y Logística

\section{Para el Grado en Marketing}

- Administración y Finanzas

- Comercio Internacional

- Gestión Comercial y Marketing
- Gestión de Alojamientos Turísticos

- Gestión de Ventas y Espacios Comerciales

- Marketing y Publicidad

- Transporte y Logística

\section{Para los Grados en Magisterio de Educación Infantil y en Magisterio de \\ Educación Primaria}

- Animación de Actividades Físicas y Deportivas

- Educación Infantil

- Integración Social

- Animación Sociocultural y Turística

\section{Para el Grado en Empresas} y Actividades Turísticas

- Gestión Comercial y Marketing

- Gestión de Ventas y Espacios Comerciales

- Gestión de Alojamientos Turísticos

- Agencias de Viajes y Gestión de Eventos

- Guía, Información y Asistencias Turísticas

\footnotetext{
* De acuerdo a lo establecido en el Real Decreto 1618/2011, de 14 de noviembre, sobre reconocimiento de estudios en el ámbito de la educación superior.
} 